\title{
Utilization of partograph and associated factors among obstetric care givers in hospitals of Western Oromia, Ethiopia, 2017
}

\author{
Habtamu Regasa ${ }^{1, *}$, Temesgen Tilahun ${ }^{2}$, Hasen Adem ${ }^{3}$ \\ ${ }^{1}$ Lecturer, Rift Valley University, Ethiopia, ${ }^{2}$ Assistant Professor, Obstetrics and Gynecology, ${ }^{3}$ Lecturer, College of Health \\ Sciences, Wollega University, Nekemte, Ethiopia
}

\section{*Corresponding Author:}

E-mail: ttamuko@yahoo.com

\begin{abstract}
Partograph is the graphic representation of labor and it is used to prevent prolonged labor with its complications. This study is aimed to assess the magnitude and determinants of partograph utilization in hospitals of Western Oromia, Ethiopia, 2017. Institution based cross-sectional study was conducted from January 2017 to April 2017 among obstetric care givers working in hospitals. Data was collected through face-to-face interview by using structured-questionnaire and analyzed by SPSS V. 20.0 . Logistic regression analyses were used to see the association of different variables. $89.1 \%$ of study participants were using partograph during the study period. $83.7 \%$ and $92.1 \%$ had satisfactory knowledge and favorable attitude on partograph utilization respectively. Factors associated with underutilization of partograph were lack of special training on partograph $(\mathrm{AOR}=0.08$, 95\% CI 0.02, 0.37), lack of local policy on partograph utilization ( $\mathrm{AOR}=0.08,95 \% \mathrm{CI} 0.02,0.36$ ) and having more than 10 deliveries in a day $(\mathrm{AOR}=0.11,95 \% \mathrm{CI} 0.02,0.65)$. On the other hand, being female obstetrics care provider $(\mathrm{AOR}=4.74,95 \%$ CI $1.22,20.03)$ and having $\geq 4$ midwives on duty ( $\mathrm{AOR}=3.20,95 \%$ CI $1.05,13.51)$ were positively associated with partograph utilization. This study revealed that knowledge, practice and attitude towards utilization of partograph were below WHO recommendation because of some modifiable factors.
\end{abstract}

Keywords: Partograph, Western Oromia, Obstetric care providers.

\section{Introduction}

Partograph is graphic representation of labor which is used by health professionals for monitoring labor progress, fetal and maternal wellbeing; handover patients' information and thus enhance teamwork. It has significant role in preventing maternal and fetal death from prolonged labor ${ }^{1-5}$ particularly in developing countries where access to and quality of medical care is limited. Despite the fact that partograph is simple and inexpensive tool, there are numerous factors rendering its utilization. Knowledge, attitude and practice of partograph utilization also varies among health professionals. ${ }^{6-9}$

In Ethiopia, its utilization is low and not consistent because of a variety of reasons even though many trainings were given on this issue by government and other nongovernmental stakeholders. ${ }^{7,9}$

\section{Material and Methods}

Study design, setting and participants: Hospital based descriptive cross sectional study design was conducted at ten hospitals in Western Oromia from January 2017 to April 2017. The hospitals were Nekemte referral hospital, seven public general hospitals (Arjo, Gida, Shambu, Dambi Dollo, Gimbi, Nejo and Begi hospitals) and two non-governmental general hospitals (Aira and Gimbi Adventist). There were nearly 4 million people living in Western Oromia. 2,377 of them were health professionals. They were from Oromo, Amhara, Gurage and Tigre ethnic groups. The study participants were all professional obstetric care givers who work in antenatal care unit, maternity, labor and delivery wards of the above hospitals.

Sample size determination and sampling techniques: The required sample size was determined by using single population proportion formula based on the following assumptions. The magnitude of partograph utilization from the research conducted in Addis Ababa, capital of Ethiopia, was $57 \%$ ( $\mathrm{p}=0.57, \mathrm{q}=0.43$ ), $\mathrm{Z}_{\alpha / 2}=$ $1.96(95 \%$ confidence interval $)$ and $\mathrm{d}=5 \%(0.05){ }^{(10)}$. After adding $10 \%$ for non-responses, the final sample size became 155. But since the total number of the population under investigation was small (224), all study participants were included in the study after obtaining informed consent.

Data collection procedures: A pre-tested structured questionnaire was developed after reviewing similar literatures. The questionnaires were prepared in English and it was designed to obtain information about study participants and different variables regarding magnitude and determinants of partograph utilization. Ten midwifery professionals were recruited and trained on how to complete the questionnaires and procedures to be followed during data collection. All completed questionnaires were reviewed each morning.

Data Processing and Analysis: The collected data was entered and analyzed by using SPSS for windows version 20.0. Descriptive analysis such as frequency, percentage, and mean, median was applied for different factors and outcomes. Logistic regressions analysis was carried out to assess the assumed associations of various factors with utilization of the outcome variables after controlling confounding. Significance level and 
association of variables were tested by using $95 \%$ confidence interval (CI) and odds ratio.

Regarding knowledge, attitude and practice of partograph utilization, we made the following definitions. For the knowledge items, we gave a score of one for correct and a score of zero for wrong answers. After doing arithmetic calculations, the knowledge was considered 'satisfactory' if the score is $\geq 60 \%$ and 'unsatisfactory' if $<60 \%$ (8). Similarly, attitude towards partograph was measured by using a 5point Likert scale. The attitude of participant was considered 'favorable' if the score was $\geq 60 \%$ and 'unfavorable' if $<60 \%$ (8).

In this study, health professionals who have been using partograph routinely or at least for a single mother during their shift were considered as partograph utilizers. On the other hand, study participants who were not using partograph at all or use it infrequently were considered as non-utilizers.

\section{Results}

Socio-demographic characteristics of study participants: Among study participants, $63.4 \%$ and $36.6 \%$ were males and females respectively. The participants were from 20 to 48 years, with a mean age of 28.6 years $(\mathrm{SD} \pm 4.8)$. 58\%, $24.3 \%$ and $17.9 \%$ were midwives, clinical nurses, health officers and general practitioners respectively (Table 1).

Table 1: Socio-demographic characteristics of study participants $(\mathbf{n}=\mathbf{2 0 2})$

\begin{tabular}{|l|c|c|}
\hline Variable & Number & Percent \\
\hline Sex & 128 & 63.4 \\
\hline Male & 74 & 36.6 \\
\hline Female & 25 & 12.3 \\
\hline Age category of the respondent \\
\hline $20-24$ & 98 & 48.5 \\
\hline $25-29$ & 49 & 24.2 \\
\hline $30-34$ & 18 & 8.9 \\
\hline $35-39$ & 12 & 5.9 \\
\hline $40+$ & 28 & 13.9 \\
\hline Profession of respondent \\
\hline $\begin{array}{l}\text { General practitioner } \\
\text { (MD) }\end{array}$ & 28 & 4.0 \\
\hline Health officer (HO) & 8 & 24.3 \\
\hline $\begin{array}{l}\text { Nurse } \\
\text { Diploma) }\end{array}$ & 49 \\
\hline $\begin{array}{l}\text { Midwife (BSC, } \\
\text { Diploma) }\end{array}$ & 117 & 58.0 \\
\hline Religion of respondents \\
\hline
\end{tabular}

\begin{tabular}{|l|c|c|}
\hline Orthodox & 49 & 24.3 \\
\hline Catholic & 14 & 6.9 \\
\hline Protestant & 112 & 55.4 \\
\hline Muslim & 22 & 10.9 \\
\hline Waqefataa & 5 & 2.5 \\
\hline Marital status & \multicolumn{2}{|l|}{} \\
\hline Single & 89 & 44.1 \\
\hline Married & 95 & 47.0 \\
\hline Divorced & 18 & 8.9 \\
\hline Total & 202 & 100.0 \\
\hline
\end{tabular}

Knowledge of study participants on partograph utilization: Of the study participants, 169 (83.7\%) and $33(16.3 \%)$ had satisfactory and unsatisfactory knowledge respectively. Majority $163(80.7 \%)$ had received in-service training on comprehensive obstetric care but only $82(40.5 \%)$ had special training on partograph utilization.

Attitude of participants on partograph utilization: Most of study participants, 187 (92.6\%), had favorable attitude while the remaining 15 (7.4\%) had unfavorable attitude towards partograph utilization. Among study participants, $184(91.1 \%)$ and $193(95.5 \%)$ agreed that using partograph reduces maternal morbidity and mortality respectively while $199(98.5 \%)$ agreed that using partograph enables health care providers to recognize obstetric complication early. From all study participants, 194 (96.0\%) agreed that using partograph reduce morbidity of newborn.

Partograph utilization, associated factors and reasons for not using it: In this study, 180(89.1\%) of study participants were used partograph for laboring mothers (Fig. 1).

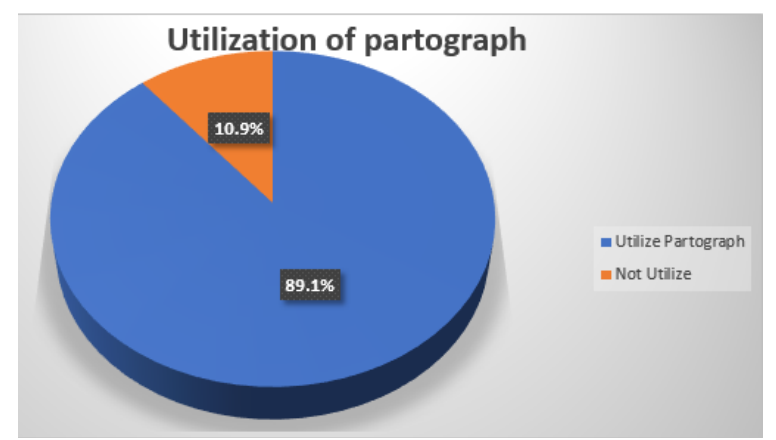

Fig. 1: Partograph utilization among study participants

Most of the study participants reported shortage of staff, work load and poor appreciation of its function as the key reasons for not using partograph (Fig. 2). 


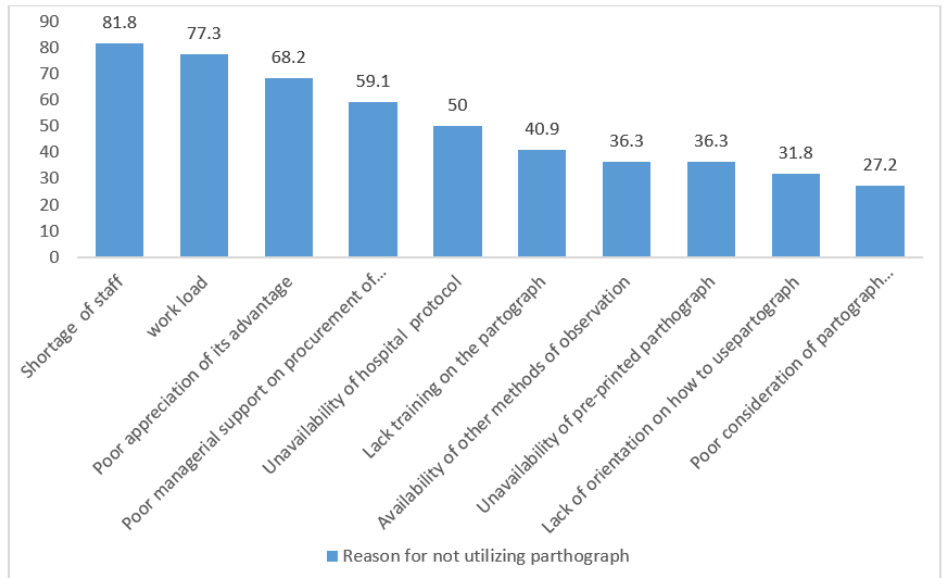

Fig. 2: Reasons for not using the partograph among study participants

Factors like lack of special training on partograph (AOR $=0.08,95 \%$ CI $0.02,0.37$ ), lack of local policy on partograph utilization $(\mathrm{AOR}=0.08,95 \% \mathrm{CI} 0.02,0.36)$ and conducting more than 10 deliveries in a day $(\mathrm{AOR}=$ $0.11,95 \%$ CI $0.02,0.65$ ) were associated with underutilization of partograph. On the other hand, being female obstetrics care provider ( $\mathrm{AOR}=4.74,95 \% \mathrm{CI} 1.22,20.03$ ) and having more or equal to four midwives on duty at a time $(\mathrm{AOR}=3.20,95 \%$ CI $1.05,13.51)$ were positively associated with partograph utilization (Table 2$)$.

Table 2: Determinants of partograph utilization among study participants $(\mathbf{n}=\mathbf{2 0 2})$

\begin{tabular}{|c|c|c|c|c|c|}
\hline \multirow{2}{*}{\multicolumn{2}{|c|}{ Variable }} & \multicolumn{2}{|c|}{ Partograph utilization } & \multirow{3}{*}{$\begin{array}{c}\text { COR (95\%) CI } \\
1\end{array}$} & \multirow{3}{*}{$\begin{array}{c}\text { AOR (95\%) CI } \\
1\end{array}$} \\
\hline & & Utilize & Not utilize & & \\
\hline \multirow[t]{2}{*}{ Sex } & Male & $120(59.4 \%)$ & $8(4.0 \%)$ & & \\
\hline & Female & $60(29.7 \%)$ & $14(6.9 \%)$ & $3.50(1.39,8.80)$ & $4.74(1.22,20.03)$ \\
\hline \multirow[t]{5}{*}{ Age in year } & $20-24$ & $20(9.9 \%)$ & $5(2.5 \%)$ & 1 & 1 \\
\hline & $25-29$ & $92(45.5 \%)$ & $6(3.0 \%)$ & $0.26(0.07,0.94)$ & $0.47(0.06,3.75)$ \\
\hline & $30-34$ & $45(22.3 \%)$ & $4(2.0 \%)$ & $0.35(0.08,1.46)$ & $0.43(0.04,3.87)$ \\
\hline & $35-39$ & $14(6.9 \%)$ & $4(2.0 \%)$ & $1.14(0.26,5,02)$ & $0.75(0.06,8.69)$ \\
\hline & $40+$ & $9(4.5 \%)$ & $3(1.5 \%)$ & $1.33(0.26,6.82)$ & $1.33(0.10,17.74)$ \\
\hline \multirow{4}{*}{$\begin{array}{l}\text { Total service } \\
\text { years }\end{array}$} & $<2$ & $69(34.2 \%)$ & $8(4.0 \%)$ & $0.19(0.05,0.67)$ & $0.11(0.01,0.79)$ \\
\hline & 2 to 5 & $66(32.7 \%)$ & $4(2.0 \%)$ & $0.10(0.02,0.42)$ & $0.03(0.01,0.30)$ \\
\hline & 5 to 10 & $35(17.3 \%)$ & $4(2.0 \%)$ & $0.19(0.04,0.81)$ & $0.06(0.01,0.70)$ \\
\hline & $>10$ & $10(5.0 \%)$ & $6(3.0 \%)$ & 1 & 1 \\
\hline \multirow{2}{*}{$\begin{array}{l}\text { Current } \\
\text { working site of } \\
\text { care provider }\end{array}$} & $\begin{array}{l}\text { Antenatal } \\
\text { care unit }\end{array}$ & $116(57.4 \%)$ & $9(4.5 \%)$ & 1 & 1 \\
\hline & $\begin{array}{l}\text { Labor } \\
\text { and } \\
\text { delivery }\end{array}$ & $64(31.7 \%)$ & $13(6.4 \%)$ & $2.61(1.06,6.45)$ & $1.67(0.48,5.80)$ \\
\hline \multirow{2}{*}{$\begin{array}{l}\text { Number of } \\
\text { midwives on } \\
\text { duty at a time }\end{array}$} & 1 to 3 & $103(51.0 \%)$ & $7(3.5 \%)$ & 1 & 1 \\
\hline & $\geq 4$ & $77(38.1 \%)$ & $15(7.4 \%)$ & $2.86(1.11,7.37)$ & $3.20(1.05,13.51)$ \\
\hline \multirow{2}{*}{$\begin{array}{l}\text { Availability \& } \\
\text { implementation } \\
\text { of managerial } \\
\text { policy }\end{array}$} & Yes & $64(31.7 \%)$ & $16(7.9 \%)$ & 1 & 1 \\
\hline & No & $116(57.4 \%)$ & $6(3.0 \%)$ & $0.20(0.07,0.55)$ & $0.08(0.02,0.36)$ \\
\hline \multirow{2}{*}{$\begin{array}{l}\text { Number of } \\
\text { deliveries in a } \\
\text { day }\end{array}$} & $>10$ & $99(49.0 \%)$ & $4(2.0 \%)$ & $0.18(0.59,0.56)$ & $0.11(0.02,0.65)$ \\
\hline & $\leq 10$ & $81(40.1 \%)$ & $18(8.9 \%)$ & 1 & 1 \\
\hline \multirow{2}{*}{$\begin{array}{l}\text { No special in- } \\
\text { service training } \\
\text { on partograph }\end{array}$} & Yes & $116(57.4 \%)$ & $4(2.0 \%)$ & $0.12(0.04,0.37)$ & $0.08(0.02,0.37)$ \\
\hline & No & $64(31.7 \%)$ & $18(8.9 \%)$ & 1 & 1 \\
\hline
\end{tabular}




\section{Discussion}

This study was aimed to identify magnitude and determinants of partograph utilization among obstetric care providers in Western Oromia hospitals. It is very crucial to use partograph to reduce maternal and new born morbidity and mortality. In our study, utilization of partograph in hospitals of Western Oromia is lower when compared to expected standard of WHO partograph utilization, which is $100 \% .^{3,5,10,11}$ This could be due to factors related to facility, human resource and/or individual level. The major ones were shortage of staff, work load and poor appreciation of its utilization among the care givers.

On the other hand, partograph utilization in current study is better than its utilization in other studies conducted in Ethiopia and other countries in Africa. This could be explained by difference in attitude of care providers, level of knowledge and in-service trainings different organizations were giving in these study areas. ${ }^{6,7,9}$

Knowledge, practice and attitude of study participants on partograph utilization was found to be higher in this study when compared with other studies in Ethiopia. The difference could be due to provision of training, orientation and joint supportive supervision from concerned bodies; and change in policy in this part of the country 3,4

Majority 92.6\%, of study participants had favorable attitude towards partograph utilization and 98.5\% agreed that using partograph enables health care providers to recognize obstetric complications. This was higher than study conducted in Northern Shoa zone, Ethiopia. ${ }^{9}$ This discrepancy might be due to difference in study area and period. This favorable attitude is so promising for future utilization of partograph in this part of the country.

Partograph utilization among female health care providers was almost about five times when compared with male health care providers. This finding may be entry point for health institutions and other stake holders to work on how to increase male involvement in partograph utilization. Having at least four midwives on duty per shift increased partograph utilization by more than three times when compared with lesser number of midwives. Thus, the authors emphasize the issue of appointing adequate number of midwives in labor ward. Like other studies in Ethiopia and other African countries, lack of local protocol and special inservice training on partograph utilization, and having many deliveries were associated with underutilization of partograph. ${ }^{6,8-10}$

Though WHO recommends partograph utilization as routine practice to observe and follow laboring mothers, there are many factors rendering its utilization. Like other studies in developing factors, there were many modifiable factors related with experience, resource, attitude and managerial commitment that affect its utilization negatively. ${ }^{4,12}$

\section{Conclusion}

This study revealed that knowledge, practice and attitude towards utilization of partograph were below WHO recommendation because of some modifiable factors.

\section{Ethical Consideration}

After fulfilling all crucial steps of research proposal, formal ethical clearance was obtained from the Ethics Review Committee of Health Sciences of Wollega University. All study participants were handled by following all rules and regulations of clinical research.

\section{Acknowledgements}

We would like to acknowledge Wollega University College of Medical and Health Sciences for giving us this opportunity to conduct this paper. Last but not least, our special thanks go to hospital managers and heads of maternity and labor ward unit for their support during data collection.

\section{References}

1. The application of the WHO partograph in the management of labor report of WHO 2014;1990-2013.

2. Mathai M. The partograph for the prevention of obstructed labor. Clin Obstet Gynecol 2009;52:256-69.

3. Maternal mortality and cause of morbidity. Estimates developed by WHO UNICEF and UNFPA 2015.

4. Maternal Health and Safe Motherhood Program. Lancet 2013;343:399-1404.

5. United Nations Populations Fund (UNFPA) and World Bank joint statement: Reduction of maternalmortality.www.who.int/reproductivehealth/publi cations/monitoring/9789241561952/en/.

6. Singh Reenadevi. Description of the utilization of partograph by midwives in the public hospital in the Umgungudlovu district, Kwazulu-natal. Durban University of Technology 2013;145-53.

7. Gemechu B, O B Chandra Sekhara Reddy. Analysis of risk factors for maternal death and delivery complications in West Shoa Zone, Oromia Region, Ethiopia: A Retrospective Study. Global Journal of Current Research 2014;3(1):36-9.

8. Fantu A, Dereje B, Worku A, Tadesse E. Assessment of knowledge and utilization of the partograph among health professionals in Amhara Region, Ethiopia. Clinical Medicine Science Journal 2013;2(2):26-42.

9. Negash W, Abdella A, Martha B, Gizachew AT. Partograph utilization and associated factors among obstetric care providers in North Shoa Zone, Central Ethiopia. Africa Health Sci 2015; 15:552-9.

10. Yisma E, Dessalegn B, Astatkie A, FessehaN. Knowledge and utilization of partograph among obstetric care givers in public health institutions of Addis Ababa, Ethiopia. BMC Pregnancy and Childbirth 2013;13(17):19.

11. Martin's, Fischer. Labor and delivery Md. India network for health, 2011. www.medline.net.

12. Federal Democratic Republic of Ethiopia, Ministry of. Health. Health Sector Transformation Plan 2015. Available on https://searchworks.stanford.edu/view/11700944. 